\title{
Improving the Performance of Dye-Sensitized Solar Cells
}

\author{
Gerrit Boschloo* \\ Department of Chemistry-Ångström Laboratory, Uppsala University, Uppsala, Sweden
}

Dye-sensitized solar cells have been investigated intensively during the last three decades. Nevertheless, there are still many aspects to be explored to further improve their performance. Dye molecules can be modified endlessly for better performance. For instance, steric groups can be introduced to slow down recombination reactions and avoid unfavorable aggregation. There is a need for more optimal dye packing on the mesoporous $\mathrm{TiO}_{2}$ surface to increase light absorption and promote a better blocking effect. Novel redox mediators and HTMs are key elements to reach higher performing DSC as they can offer much higher output voltage than the traditional triiodide/iodide redox couple.

Keywords: mesoporous $\mathrm{TiO}_{2}$, recombination, electron lifetime, cobalt-complex, maximum power point, organic dyes

\section{OPEN ACCESS}

Edited by:

Stefano Caramori,

University of Ferrara, Italy

Reviewed by:

Thomas Stergiopoulos, Aristotle University of Thessaloniki,

Greece

Claudia Barolo,

University of Turin, Italy

${ }^{*}$ Correspondence:

Gerrit Boschloo

gerrit.boschloo@kemi.uu.se

Specialty section:

This article was submitted to Physical Chemistry and Chemical

Physics,

a section of the journal

Frontiers in Chemistry

Received: 30 November 2018 Accepted: 28 January 2019 Published: 14 February 2019

Citation: Boschloo G (2019) Improving the Performance of Dye-Sensitized Solar Cells. Front. Chem. 7:77.

doi: 10.3389/fchem.2019.00077

\section{INTRODUCTION}

Dye-sensitized solar cells (DSCs) have attracted much attention in recent years, because of their good photovoltaic performance, specifically under low-light conditions, as well as their flexibility in terms of colors and appearance, their relatively simple fabrication procedures and their potential low cost. Efficient dye-sensitized solar cells (DSCs) were first developed in the 1990s marked by the breakthrough work by O'Regan and Grätzel (1991) who first used mesoporous $\mathrm{TiO}_{2}$ electrodes prepared from colloidal $\mathrm{TiO}_{2}$ nanoparticles (O’Regan and Grätzel, 1991).

The working mechanism of DSC differs much from other types of solar cells (O'Regan and Grätzel, 1991; Hagfeldt et al., 2010). In their original conception, the DSC is a photoelectrochemical solar cell, consisting of a dye-sensitized mesoporous $\mathrm{TiO}_{2}$ working electrode (WE), a redox electrolyte and a counter electrode (CE). Both the WE and CE can be (semi) transparent, which allows for illumination of the solar cell from either side. Dye molecules, equipped with suitable anchoring groups, are adsorbed as a monolayer onto the mesoporous $\mathrm{TiO}_{2}$ electrode. When the dyes absorb light, the excited molecules can inject electrons into the conduction band of $\mathrm{TiO}_{2}$ (electron transfer (ET) reaction 1 in Figure 1). A redox mediator in the electrolyte regenerates the resulting oxidized dye molecules (ET 2). The oxidized form of the mediator is responsible for transport of positive charge to the counter electrode by means of diffusion. Finally, electrons in the $\mathrm{TiO}_{2}$ are collected at the underlying fluorine-doped tinoxide (FTO)-coated glass substrate and move through an external circuit to the counter electrode, where they reduce the oxidized redox mediator (ET 3), thus completing the cycle. A schematic presentation of these processes is shown in Figure 1.

A number of recombination reactions in the DSC compete with the forward processes described above. Radiative and non-radiative de-excitation of the dye competes with electron injection from the excited dye into the conduction band of $\mathrm{TiO}_{2}$. Furthermore, electrons in the $\mathrm{TiO}_{2}$ can recombine with oxidized dye molecules (ET 4) or to the oxidized form of the redox mediator (ET 5). For optimized DSC systems the incident photon to current conversion efficiency (IPCE) is 


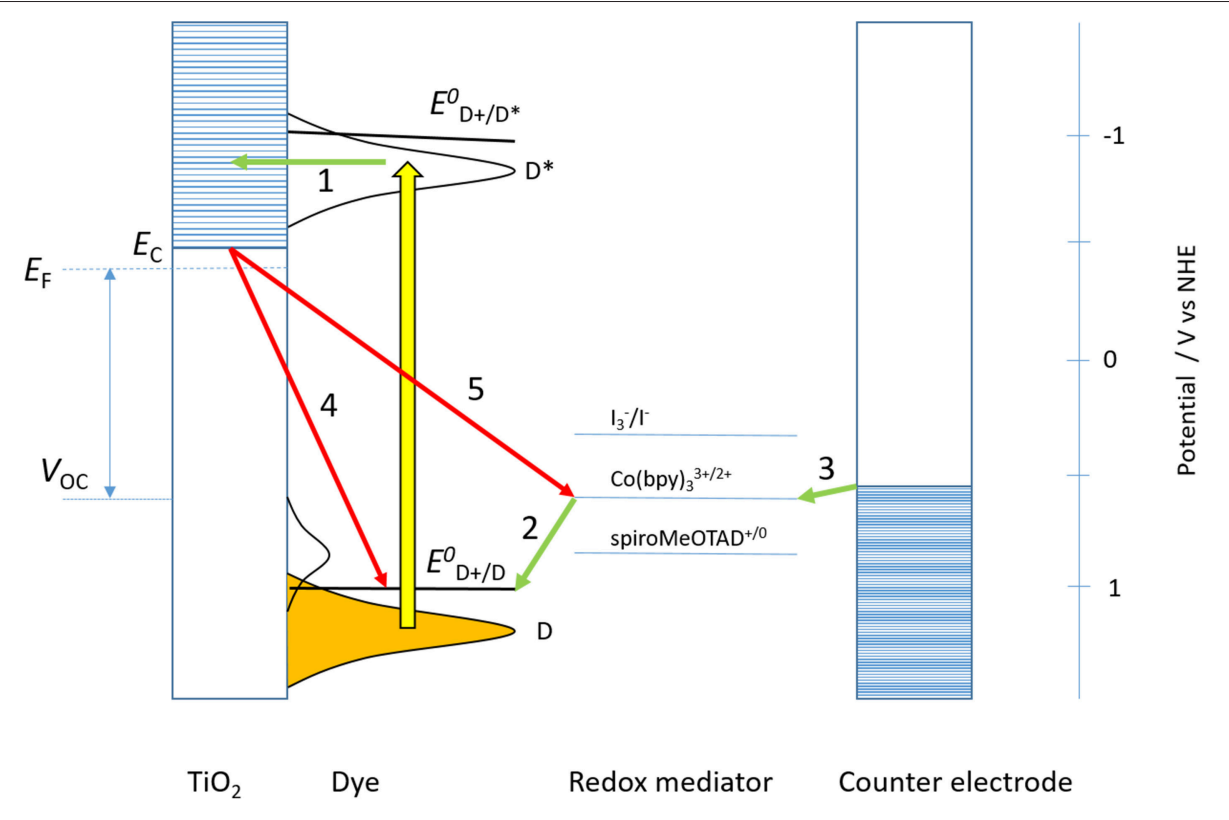

FIGURE 1 | Energy scheme and working mechanism of a dye-sensitized solar cell. Electron transfer reactions are indicated with numbers and arrows (green for forward, red for recombination) that are referred to in the text. The energy levels of different redox mediators are indicated (spiro-MeOTAD is a solid-state hole conductor).

about $90 \%$. Since there are some reflection and transmission losses, this implies that every absorbed photon gives an electron in the external circuit under the measurement conditions used, typically under short-circuit conditions. Under operating conditions, when the solar cell delivers maximum power output (in the maximum power point, MPP), the IPCE is significantly lower and there are both current and voltage losses. In order to fully optimize the DSC these losses must be minimized, as will be discussed in section Limiting Factors in the DSC.

The triiodide/iodide $\left(\mathrm{I}_{3}^{-} / \mathrm{I}^{-}\right)$redox couple is most frequently used in DSCs. However, this complex redox couple has some serious limitation, as pointed out in our previous work (Boschloo and Hagfeldt, 2009). Specifically, its formal reduction potential $\left(E^{0}\right)$ is relatively negative $(+0.35 \mathrm{~V}$ vs. NHE) compared to the $E^{0}\left(\mathrm{D}^{+} / \mathrm{D}\right)$ of typical dyes (located at ca. $1 \mathrm{~V}$ vs. NHE), resulting in a large loss of more than $0.5 \mathrm{~V}$. The origin lies in the multistep regeneration mechanism that involves formation of the $\mathrm{I}_{2}^{-}$radical as a reaction intermediate. Furthermore, triiodide is quite strongly colored and there are issues with long-term stability (particles). In short, triiodide/iodide is not the avenue to DSC with higher performance. Several promising alternative redox mediators will be discussed in section Components for more efficient DSCs.

A disadvantage compared to other solar cell technologies is the use of a liquid redox electrolyte in efficient DSCs. This makes encapsulation problematic and it makes the devices less compatible with other solid-state photovoltaic technologies. The liquid redox electrolyte can, however, be replaced by a solidstate hole conductor in DSCs to make fully solid-state DSC (Bach et al., 1998). Unfortunately, this usually comes at the cost of faster recombination and a lower overall performance.
In order to make significant impact in the field of photovoltaics, the performance of DSC needs to be further improved. Their record efficiencies under 1 sun illumination, shown in Table 1, are just over 10\%, which is lower than that of most other competing photovoltaic technologies. For indoor applications, however, DSC holds the record in performance with $32 \%$ at 1,000 lux (Cao et al., 2018). One reason is for this that the absorption spectrum of the dye can ideally match the emission spectrum of an indoor light source.

This perspective focusses most on the efficiency of DSCs, but in the end, their long-term stability is equally important for practical applications.

\section{LIMITING FACTORS IN THE DSC}

The Shockley-Queisser (SQ) limit gives the maximum efficiency attainable for a single junction photovoltaic device, which is $33.8 \%$ under $1,000 \mathrm{~W} \mathrm{~m}^{-2}$ solar irradiation with AM1.5G spectral distribution (Green, 2012). While this limit was derived for semiconductor devices, it is in principle also valid for DSCs. The bandgap $E_{\mathrm{g}}$ sets the range for light absorption: all photons with energies larger than $E_{\mathrm{g}}$ are absorbed and contribute to photocurrent, those with smaller energies are transmitted and not used. The only recombination processes that are considered in the derivation of the SQ limit are radiative processes, since these are unavoidable. Any non-radiative recombination processes will further lower the efficiency. According to the SQ analysis the optimal bandgap is $1.3 \mathrm{eV}$; the maximum obtainable efficiency gradually decreases to $25 \%$ for $E_{\mathrm{g}}=1.9 \mathrm{eV}$. This would correspond to a dye with an absorption onset wavelength of 
TABLE 1 | Redox mediators and dyes used in high performance dye-sensitized solar cells.

\begin{tabular}{|c|c|c|c|c|}
\hline Redox couple $\left(R^{+} / R\right)$ & $\begin{array}{c}E^{0} / \mathrm{V} \text { vs. } \\
\text { NHE }\end{array}$ & Dye (type) & $\begin{array}{l}\text { Selected record solar cell } \\
\text { efficiencies }\left(V_{\text {OC }}, J_{S C}, F F\right)\end{array}$ & Year, reference (comment) \\
\hline$\left.\right|_{3}-/ \mid-$ & +0.35 & $\begin{array}{l}\text { Black dye (Ru complex) + } \\
\text { Y1 }\end{array}$ & $\begin{array}{l}11.9 \%\left(0.744 \mathrm{~V}, 22.5 \mathrm{~mA} \mathrm{~cm}^{-2}\right. \\
0.712)\end{array}$ & 2011 (Han et al., 2012) \\
\hline $\mathrm{Co}(\mathrm{bpy})_{3}^{3+1}$ & +0.56 & $\begin{array}{l}\text { YD2-o-C8 (porphyrin) + } \\
\text { Y123 (DpA) }\end{array}$ & $\begin{array}{l}12.3 \%\left(0.935 \mathrm{~V}, 17.7 \mathrm{~mA} \mathrm{~cm}^{-2} \text {, }\right. \\
0.74)\end{array}$ & 2011 (Yella et al., 2011) \\
\hline & & $\mathrm{R} 6(\mathrm{DpA})$ & $\begin{array}{l}12.6 \%\left(0.850 \mathrm{~V}, 19.7 \mathrm{~mA} \mathrm{~cm}^{-2}\right. \\
0.754)\end{array}$ & 2018 (Ren et al., 2018) \\
\hline Co(p & +0.62 & Adeka-1+ LEG4 (DpA) & $\begin{array}{l}14.3 \%\left(1.01 \mathrm{~V}, 18.3 \mathrm{~mA} \mathrm{~cm}^{-2}\right. \\
0.771)\end{array}$ & $\begin{array}{l}2015 \text { (Kakiage et al., 2015) } \\
\text { (open device) }\end{array}$ \\
\hline $\mathrm{Co}(\mathrm{bp}$ & +0.86 & Y123 & $\begin{array}{l}10.1 \%\left(0.998 \mathrm{~V}, 13.1 \mathrm{mAcm}^{-2}\right. \\
0.774)\end{array}$ & 2012 (Yum et al., 2012) \\
\hline Spiro-MeOTAD +/0 HTM & +0.75 & S5 (DpA) & $\begin{array}{l}7.81 \%\left(0.83 \mathrm{~V}, 12.9 \mathrm{~mA} \mathrm{~cm}^{-2}\right. \\
0.73)\end{array}$ & 2017 (Shen et al., 2017) \\
\hline $\mathrm{Cu}(\mathrm{tmp})_{2}^{2+/+} \mathrm{HTM}$ & +0.91 & WS72 (DpA) & $\begin{array}{l}\text { 13.8\% (1.07 V, } 11.7 \mathrm{~mA} \mathrm{~cm}^{-2} \text {, } \\
0.79)\end{array}$ & 2018 (Zhang et al., 2018) \\
\hline
\end{tabular}

$650 \mathrm{~nm}$, a value commonly obtained for efficient sensitizing dyes in the DSC. The corresponding theoretical photocurrent under short-circuit conditions, $J_{\mathrm{SC}}$, would be $17 \mathrm{~mA} \mathrm{~cm}^{-2}$.

While the maximum open circuit potential $\left(V_{\mathrm{OC}}\right)$ in semiconductor photovoltaics has $E_{\mathrm{g}} / e$ as the absolute upper limit, for DSC the upper limit is set by the difference between the conduction band potential $E_{\mathrm{C}}$ of the $\mathrm{TiO}_{2}$ on one side and the redox potential of the electrolyte on the other side. This value will always be smaller than the "bandgap" of the dye. $E_{\mathrm{C}}$ of $\mathrm{TiO}_{2}$ anatase is about $-0.5 \mathrm{~V}$ vs. NHE when its surface is uncharged 
(i.e., at neutral $\mathrm{pH}$, without specific ion adsorption, and without electron accumulation). This level can be altered by additives in the electrolyte that lead to a change in the surface charge or alter the dipole moment at the semiconductor/electrolyte interface. Alternatively, $E_{\mathrm{C}}$ can be changed by chemical modification of the $\mathrm{TiO}_{2}$, for instance by incorporation of $\mathrm{Mg}$ in the structure, which can to shift $E_{\mathrm{C}}$ to more negative potential, to about $-0.7 \mathrm{~V}$ vs. NHE (Kakiage et al., 2016). Ultra-thin metal oxide layers (such as $\mathrm{Al}_{2} \mathrm{O}_{3}$ ) covering the mesoporous $\mathrm{TiO}_{2}$ can also affect the location of $E_{C}$ (Kay and Grätzel, 2002). Such layers also affect the kinetics of interfacial electron transfer reactions, and may be used for fine-tuning of the properties of the DSC.

The electrochemical potential of electrons in the $\mathrm{TiO}_{2}$, usually referred to as the Fermilevel $E_{\mathrm{F}}$, is given by:

$$
E_{F}=E_{C}-\frac{k_{B} T}{e} \ln \frac{n_{c}}{N_{c}}
$$

where, $k_{B}$ is the Boltzmann constant, $T$ the absolute temperature, $e$ the elementary charge ( $k_{B} T / e$ is $0.0257 \mathrm{~V}$ at room temperature), $n_{c}$ is the density of conduction band electrons, and $N_{c}$ is the effective density of electronic states at the bottom of the conduction band. $N_{c}$ is a material constant and is about $10^{20}$ $\mathrm{cm}^{-3}$ for $\mathrm{TiO}_{2}$ anatase. Under illumination at open-circuit conditions $E_{\mathrm{F}}$ depends on $n_{\mathrm{c}}$, which depends in turn on the generation flux of injected electrons and the rate constants for electron recombination. As a rule of thumb, $E_{\mathrm{F}}$ is about $0.1 \mathrm{~V}$ more positive than $E_{\mathrm{C}}$ at 1 sun.

Formal reduction potentials of a series of redox mediators for DSC are listed in Table $\mathbf{1}$ along with obtained record efficiencies in DSCs. Initial work on DSCs focused on the $\mathrm{I}_{3}^{-} / \mathrm{I}^{-}$redox couple, which has very favorable electron transfer kinetics, giving very low recombination losses and high $J_{\mathrm{SC}}$. This comes, however, at the cost of a relatively low $V_{\mathrm{OC}}$ due to the rather negative value of the redox potential. Successful alternative redox mediators have more positive redox potential and can provide higher $V_{\mathrm{OC}}$. Nearly all of these redox mediators give, however, faster electron recombination to oxidized redox mediators, thereby lowering the Fermi level on the $\mathrm{TiO}_{2}$ under operational conditions.

The highest reported $V_{\text {OC }}$ for a DSC is $1.4 \mathrm{~V}$, and was obtained for a $\mathrm{Mg}$-doped $\mathrm{TiO}_{2}$ with additional surface modification by $\mathrm{MgO}$ and $\mathrm{Al}_{2} \mathrm{O}_{3}$, sensitized by a coumarin dye, and in combination with the $\mathrm{Br}_{3}^{-} / \mathrm{Br}^{-}$redox couple (Kakiage et al., 2016). The doping and surface modification of the $\mathrm{TiO}_{2}$ raised the conduction band edge to about $-0.7 \mathrm{~V}$ vs. NHE, while the formal potential of the redox couple is about $+0.9 \mathrm{~V}$ vs. NHE.

The best performing DSCs with $\mathrm{Co}(\mathrm{bpy})_{3}$ redox electrolyte can obtain a $V_{\text {OC }}$ of about $0.9 \mathrm{~V}$. The $V_{\text {OC }}$ for best ssDSC with spiro-MeOTAD hole conductor is about $0.8 \mathrm{~V}$. As the redox potentials of the $\mathrm{Co}$ and the spiro:MeOTAD hole conductor differs by about $0.2 \mathrm{~V}$, this implies that Fermi level in $\mathrm{TiO}_{2}$ is about $0.3 \mathrm{eV}$ lower in the mesoporous $\mathrm{TiO}_{2}$ for the ssDSC device under open circuit illumination conditions. This is due to much faster electron recombination kinetics. Using Equation 1, it can be estimated that the concentration of conduction band electrons is many orders of magnitude lower in the ssDSC than in the Co(bpy) ${ }_{3}$-DSC.
As indicated in Figure 1, the energy level of the ground state dye displays a Gaussian distribution, with an average energy that is below the formal redox energy by an amount equal to the reorganization energy $\lambda$. Upon excitation energy levels $D^{*}$ should overlap with acceptor levels in the conduction band of $\mathrm{TiO}_{2}$ for efficient electron injection. A lower value of $\lambda$ would allow for closer matching between $E_{\mathrm{C}}$ of the semiconductor and the calculated standard potential for the excited dye, $E^{0}\left(\mathrm{D}^{+} / \mathrm{D}^{*}\right)$ and less voltage loss in the DSC. The reorganization energy of the dye is due to internal molecular reorganization of the dye when it changes redox state and external reorganization of the solvent shell. Due to the absence of solvent, reorganization energies should be lower in solid-state DSC.

The electron injection (reaction 1 in Figure 1) competes with radiative and non-radiative decay processes of the excited dye. A long-lived excited state of the dye it therefore favorable. Excessive energy losses during the injection process should, however, be avoided (Haque et al., 2005). After injection the electrons travel through the mesoporous film and are collected at the FTO substrate. Electron recombination to oxidized dye (reaction 4) and the oxidized form of the redox mediator (reaction 5) must be avoided. The electron lifetime is the inverse of the sum of the rate constants of both recombination processes. It is frequently assumed that electron recombination to the oxidized dye in negligible, as the dye regeneration is usually rather fast on a microsecond time scale (reaction 3). Under solar cell operation conditions, however, a large concentration of electrons in accumulated in the mesoporous $\mathrm{TiO}_{2}$, which will accelerate the recombination process significantly (Haque et al., 2000). Haque et al. determined that the halftime for recombination to oxidize Ru-dye (N3) decreased to about $1 \mathrm{~ns}$ when a potential of $-0.3 \mathrm{~V}$ vs. NHE was applied on the mesoporous $\mathrm{TiO}_{2}$ electrode (Haque et al., 2000). Therefore, significant recombination to the oxidized sensitizer can take place in the dye-sensitized solar operating at MPP conditions.

The kinetics of electron recombination to the redox electrolyte depends very strongly on the nature of the oxidized form of the redox mediator. It is very slow for triiodide, faster for cobalt mediators and faster still for triphenylamine based mediators or hole conductors. Crucial for the successful use of the latter two is that kinetics can be slowed down by structural modification of the dye: group can slow down the recombination process.

A long electron lifetime is favorable for the DSC as it will improve the $V_{\text {OC }}$. In regular liquid-electrolyte DSCs the electron lifetime is typically $1-10 \mathrm{~ms}$ under open-circuit conditions and one sun illumination. The electron transport time should be smaller than the lifetime to avoid losses during transport. Typical values under short-circuit conditions are about one order of magnitude smaller than the electron lifetime. Under operational condition (at MPP) the electron transport in the mesoporous $\mathrm{TiO}_{2}$ is not a limiting factor, since transport becomes faster upon more electron accumulation, resulting in a more negative potential for $E_{\mathrm{F}}$. In other words, the transport resistance $R_{\mathrm{tr}}$ becomes smaller when the $\mathrm{TiO}_{2}$ /electrolyte capacitor $C_{\mathrm{TiO} 2}$ is charged, see Figure 2.

Under open-circuit conditions the external resistor $R_{\text {ext }}$ is infinite. All current then goes through the recombination 


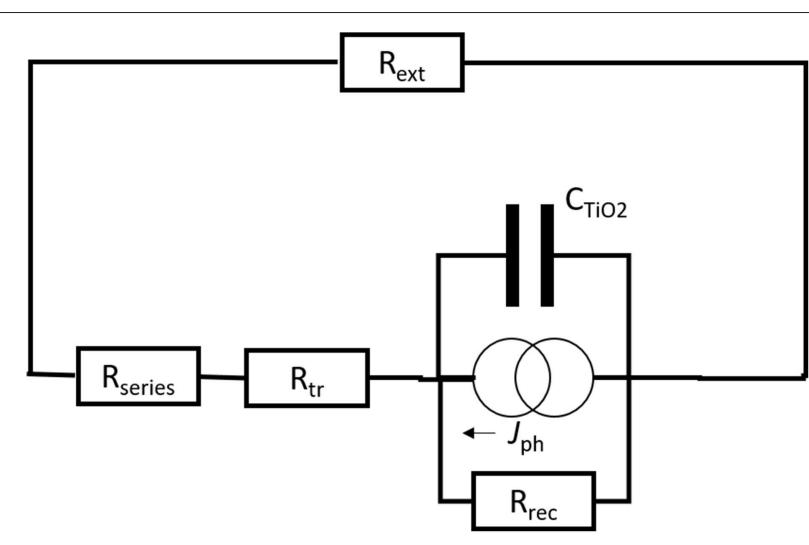

FIGURE 2 | Schematic electrical diagram of a dye-sensitized solar cell. A current generator give a photocurrent $J_{\text {ph }}$, which charges the capacitor. The current flow is through $R_{\text {series }}+R_{\text {tr }}+R_{\text {ext }}$ and through $R_{\text {rec. }}$.

resistance $R_{\text {rec }}$. This is the normal condition to measure electron lifetime $\tau$, which is equal to $R_{\mathrm{rec}} \times C_{\mathrm{TiO} 2}$. Under short circuit conditions $R_{\text {ext }}$ is equal to 0 . The charge collection efficiency : $\eta_{\mathrm{CC}}$ is then given by $R_{\text {rec }} /\left(R_{\text {series }}+R_{\mathrm{tr}}+R_{\text {rec }}\right)$, where $R_{\text {series }}$ is the series resistance discussed below. Under MPP-conditions we find: $\eta_{\mathrm{CC}}=R_{\mathrm{rec}} /\left(R_{\text {series }}+R_{\mathrm{tr}}+R_{\mathrm{ext}}+R_{\mathrm{rec}}\right)$.

Based on this simple scheme, it is evident that the recombination resistance must be maximized to increase current collection efficiency and output voltage across the external resistor under MPP conditions. The recombination resistance will decrease with increasing thickness and the surface area of the mesoporous electrode. Increasing thickness will, however, increase the generated photocurrent. For every specific DSC system there is an optimum film thickness: Typical values are $\sim 10 \mu \mathrm{m}$ for regular liquid electrolyte DSC and $\sim 2 \mu \mathrm{m}$ for solidstate DSCs.

Some series resistance losses are unavoidable in practical DSC devices. There will be some resistance due to the FTO substrates that are used, due to the charge transfer resistance at the counter electrode and due to diffusion resistance in the electrolyte. Han et al. make a detailed analysis of resistances in the DSC, and minimized $R_{\text {series }}$ down to $1.8 \mathrm{Ohm} \mathrm{cm}^{-2}$ by optimizing the catalytic performance of the counter electrode and the electrolyte distance between working and counter electrode (Han et al., 2005). By minimizing the distance between WE and CE the diffusion resistance in the electrolyte is minimized. There is, however, still a remaining resistance due diffusion of the redox mediator in the pores of the working electrode. Shortcircuiting between WE and CE must also be avoided. The use of PEDOT on the counter electrode seems to prevent short circuiting (Cao et al., 2018).

\section{COMPONENTS FOR MORE EFFICIENT DSCS}

\section{Mesoporous Metal Oxide Electrodes}

Mesoporous $\mathrm{TiO}_{2}$ (anatase) is by far the most used wide-bandgap semiconductor electrode used in DSC, and so far the most successful. In several studies the nanoparticle size, film porosity, and $\mathrm{TiCl}_{4}$ after treatment (Ito et al., 2008) have been optimized, but the optimal parameters for a specific dye-sensitized solar cell system depends strongly on dye and redox mediator system. For instance, more porous mesoporous films are best for DSCs with cobalt complex as redox mediator. An additional reflective $\mathrm{TiO}_{2}$ layer is usually added on top of a transparent $\mathrm{TiO}_{2}$ layer for improved light harvesting (Ito et al., 2008). Alternatively, reflecting particles (Wang et al., 2004) or voids (Hore et al., 2005) can be incorporated into the mesoporous film. Surface modification with ultra-thin metal oxides can be beneficial (Kay and Grätzel, 2002; Kakiage et al., 2015). Nevertheless, some properties of $\mathrm{TiO}_{2}$ are not ideal: $\mathrm{TiO}_{2}$ is a well-known photocatalyst. The bandgap of $\mathrm{TiO}_{2}$ anatase is $3.2 \mathrm{eV}$, which implies that light below $390 \mathrm{~nm}$ can excite the semiconductor, which leads to highly reactive holes. The holes may lead the destructive oxidation reactions with organic components of the DSC. UV filters are therefore generally used for long-term stability studies of DSC devices under full sunlight conditions. There are ways to minimize the photocatalytic action of $\mathrm{TiO}_{2}$, for instance by addition of an ultrathin layer of $\mathrm{Al}_{2} \mathrm{O}_{3}$ or $\mathrm{MgO}$ (Kay and Grätzel, 2002).

The use of a mesoporous semiconductor with a higher bandgap is advantageous. $\mathrm{SnO}_{2}$ with $E_{\mathrm{g}}$ of $3.6 \mathrm{eV}$ will not absorb as much UV light from the solar spectrum. $\mathrm{SnO}_{2}$ has successfully used been used in DSC, but its $E_{\mathrm{C}}$ is located at more positive potential by about $0.5 \mathrm{~V}$ compared to $\mathrm{TiO}_{2}$, which limits its performance due to low voltage output. By covering the $\mathrm{SnO}_{2}$ with an ultrathin metal oxide layer (such as $\mathrm{ZnO}, \mathrm{Al}_{2} \mathrm{O}_{3}$, or $\mathrm{MgO}$ ) a much improved voltage can be obtained (Kumara et al., 2001; Kay and Grätzel, 2002).

$\mathrm{ZnO}$ has been studied intensively as a nanostructured electrode in a wide variety of morphologies in the DSC (Zhang et al., 2009). Although there are claims that its better electron transport properties should make $\mathrm{ZnO}$ a better nanostructured electrode for DSC, no improved performance is found compared to the traditional mesoporous $\mathrm{TiO}_{2}$ electrodes. This is because the electron transport is not a limiting factor for the DSC under operational conditions (at the MPP). In general, other metal oxides can function a mesoporous electrode in DSC devices, but so far their performance is lower than that of their $\mathrm{TiO}_{2}$ counterparts.

\section{Dyes}

As will be discussed later, there is a requirement of thinner mesoporous $\mathrm{TiO}_{2}$ electrodes set by new redox mediators for DSC and hole conductors for ssDSC. Therefore, there is a need for dyes with higher extinction coefficients than the traditional $\mathrm{Ru}$ complex based dyes. Organic dyes are therefore preferred, as is reflected in Table 1 with best performing DSCs. Structures and some absorption parameters of selected dyes are displayed in Figure 3. Many successful organic dyes have a donor-pi-acceptor $(\mathrm{DpA})$ structure, which leads to electron density movement toward the acceptor part upon photoexcitation. Typically, the binding group is incorporated in the acceptor part, as in the case of cyanoacrylic acid. 


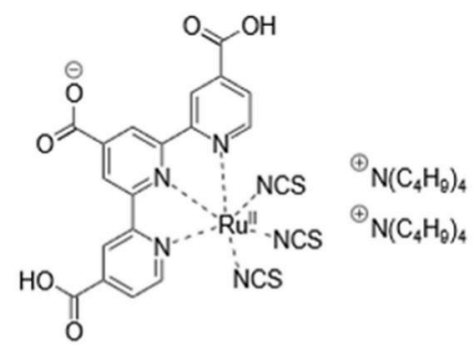

Black dye: $\lambda_{\max } 620$ (7.5), $E_{0-0}=1.5 \mathrm{eV}$

\section{LEG4: $\lambda_{\max } 541$ (49), $E_{0-0}=2.0 \mathrm{eV}$}

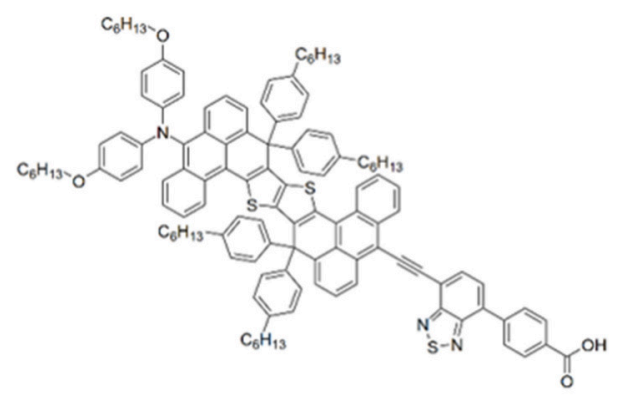

R6: $\lambda_{\max } 631(82), E_{0-0}=1.77 \mathrm{eV}$

\section{YD2-o-C8: $\lambda_{\max } 448$ (212), 645 (31), $E_{0-0}=$ $1.9 \mathrm{eV}$}

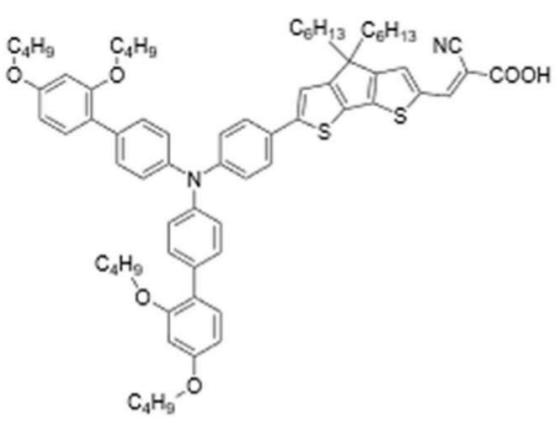

FIGURE 3 | Structures of efficient molecular sensitizers for DSC, with absorption maximum ( $\lambda$ max) in nm, extinction coefficient (in $10^{3} \mathrm{M}^{-1} \mathrm{~cm}^{-1}$ ) and zero-zero transition energy $\left(E_{0-0}\right)$. LEG4 is structurally nearly identical to $Y 123$, having butoxy-groups instead of hexoxy.

The dye structure has an important role in their overall performance. A good blocking behavior is crucial for successful use in combination with the novel redox mediators or hole conductors. Steric groups can slow down the electron transfer between $\mathrm{TiO}_{2}$ and oxidized redox mediator or hole conductor (Feldt et al., 2010).

A further requirement for optimized performance is that of dyes with relatively long excited state lifetime and high fluorescence yield. Any fast deactivation pathways should be avoided as it will affect the performance negatively. If the excitation lifetime is longer, the injection efficiency will increase. Wang et al. developed a series of highly fluorescent organic dyes with improved lifetimes, such as the R6 with an fluorescent lifetime of 260 ps for R6 adsorbed on mesoporous $\mathrm{Al}_{2} \mathrm{O}_{3}$ film (Ren et al., 2018).

Co-sensitization is a successful way to improve performance of the DSC. Record devices are usually based on co-sensitized solar cells, see Table 1. Strong and panchromatic light absorption can be achieved by selecting suitable dyes. In several cases, co-sensitization has the beneficial effect of decreasing dye aggregation (Ogura et al., 2009; Hao et al., 2016a). Furthermore, a higher dye load can be obtained. An interesting approach is to use dyes with different binding groups that do not compete for the same binding sites on $\mathrm{TiO}_{2}$. Shibayama et al. successfully combined the black dye (with carboxylic acid binding groups) with an organic dye possessing a pyridine binding group (Shibayama et al., 2014). They demonstrated that the dyes adsorbed to different binding sites.

\section{Redox Mediators}

Cobalt-based redox mediators have been tested for DSC since 2001 (Nusbaumer et al., 2001; Sapp et al., 2002) but their breakthrough came later in 2010 by the work of Feldt et al. (2010) who first demonstrated efficient DSCs with cobalt complex based redox mediators by selecting dyes with suitable properties. In contrast to the triiodide/iodide system, cobalt complexes can exhibit a wide range of redox potentials, depending on the chemical structure of their ligands. Variation of counter ions of these complexes is also important: this can strongly affect solubility in different solvents. It allows, for instance, for use of these redox mediators in water-based electrolytes (Ellis et al., 2016). Interestingly, good stability has been reported for electrolytes based on water (Ellis et al., 2016), or containing large concentrations of water (Law et al., 2010), which may open up for more environmentally friendly solar cell devices. The structures and redox potentials of cobalt complexes are shown in Table $\mathbf{1 .}$ 

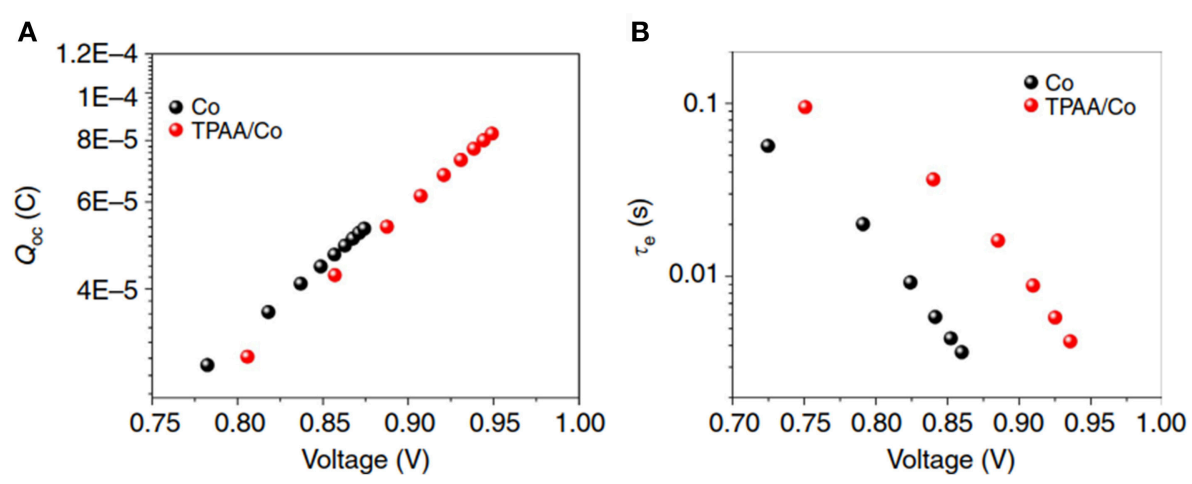

FIGURE 4 | Effect of addition of a TPA electron donor to Co(bpy) ${ }_{3}$ electrolyte in a DSC. (A) Charge extraction and (B) electron lifetime measurements as function of $V_{O C}$ in a DSC with and without additive (Hao et al., 2016b).

Recent investigations in our group clearly point to a problem of the present generation of cobalt redox mediators: they have relatively slow electron transfer kinetics (Hao et al., 2016b). The slow reduction of $\mathrm{Co}^{3+}$ species is favorable, as it gives slow kinetics for electron recombination with $\mathrm{Co}^{3+}$. On the other hand, the relatively slow regeneration of oxidized dye molecules by $\mathrm{Co}^{2+}$ is a critical issue that will limit the DSC performance. This was not recognized in earlier work of cobaltbased DSC. Addition of a rapid electron donor, such as a triphenylamine TPA, leads to very rapid regeneration of the oxidized dye molecules, which is on the sub-ns timescale (Hao et al., 2016b). The oxidized donor is in turn reduced by the $\mathrm{Co}^{2+}$ species. As a result, much higher $V_{\mathrm{OC}}$ was found and a marked increase in the electron lifetime, see Figure 4. The recombination between electron in $\mathrm{TiO}_{2}$ and oxidized dye molecules is strongly suppressed by the TPA additive, demonstrating that there was much recombination without this additive. As a result, the $V_{\mathrm{OC}}$ increased by about $100 \mathrm{mV}$, while the charge extraction experiment showed that the band edge level of the $\mathrm{TiO}_{2}$ was unchanged.

Interestingly, addition of the electron donor leads to an intermediate redox level in the DSC. This is not unlike the situation of the triiodide/iodide electrolyte, where the diiodide radical gives an intermediate redox level (Boschloo and Hagfeldt, 2009).

Another recent redox mediator development, largely driven by our research group, is that of the use of copper complexes (Freitag et al., 2015, 2016; Saygili et al., 2016). These mediators display faster dye regeneration kinetics compared to cobalt complexes (Freitag et al., 2016). Unexpectedly, relatively long electron lifetimes were observed. Very recent research from Hamann demonstrated that the $\mathrm{Cu}^{2+}$ state is chemically unstable and a $\mathrm{Cu}$ complex with 4-tert butylpyridine is formed, having a more positive potential and displaying slow electron transfer kinetics (Wang and Hamann, 2018).

\section{SOLID-STATE DSCS}

In order to make solid-state DSCs, the liquid redox electrolyte can be replaced by a solid hole transporting material (HTM). Most promising results have been achieved with molecular organic hole conductors such as spiro-MeOTAD, conduction polymers such as PEDOT, and very recently, with metal complexes (Freitag et al., 2015).

Organic small-molecular HTMs like spiro-MeOTAD give very rapid dye regeneration in the picosecond regime. While pore filling can be an issue, usually full contact between dye and HTM can be achieved for relatively thin mesoporous $\mathrm{TiO}_{2}$ films, even when the pore filling fraction is well below 100\% (Snaith et al., 2008; Cappel et al., 2009; Melas-Kyriazi et al., 2011). The main limitations of ssDSC arises from the very fast recombination between electrons in $\mathrm{TiO}_{2}$ with holes in the HTM (Snaith et al., 2008; Melas-Kyriazi et al., 2011). This limits the performance of ssDSC by lowering the output voltage significantly.

The surprising finding that dried-out DSC with Cu-complex redox electrolyte were still functioning as efficient solar cells, led to new type of ssDSC, the so-called zombie solar cell (Freitag et al., 2015). Recent optimization led to a record efficiency of $11.7 \%$ so far (Zhang et al., 2018). Unlike other HTMs, relatively long electron lifetimes are found and relatively thick $\mathrm{TiO}_{2}$ films can be used. The precise nature of the amorphous driedelectrolyte HTM, containing $\mathrm{Cu}(\mathrm{tmbpy})_{2}$, LiTFSI, and perhaps 4-tert butylpyridine needs to be explored.

In general, ssDSC are highly attractive for practical application, but their performance needs to be improved. The introduction of an intermediate redox level may be helpful: it could remove the formed holes rapidly away from the $\mathrm{TiO}_{2} /$ dye interface.

\section{CONCLUDING REMARKS}

Despite three decades of intense research on dye-sensitized solar cells, there are still many aspects to be explored to further improve their performance. Nearly infinite types of modifications of dye molecules are possible, where steric groups can be introduced to slow down recombination reactions. There is a need for more optimal dye packing on the $\mathrm{TiO}_{2}$ surface to increase light absorption and to achieve a better blocking effect. Co-sensitization offers good possibilities in this respect. Novel 
redox mediators and HTMs are key to higher performing DSC as they can offer much higher output voltage than the traditional triiodide/iodide redox couple. High-performance DSC are of interest for many applications, ranging from power source for consumer electronics, to building integrated PV and large-scale power generation. The option of high transparency in the nearinfrared region also opens up for the use of DSC as a top cell in tandem solar cells devices.

\section{REFERENCES}

Bach, U., Lupo, D., Comte, P., Moser, J. E., Weissortel, F., Salbeck, J., et al. (1998). Solid-state dye-sensitized mesoporous $\mathrm{TiO}_{2}$ solar cells with high photon-toelectron conversion efficiencies. Nature 395, 583-585. doi: 10.1038/26936

Boschloo, G., and Hagfeldt, A. (2009). Characteristics of the iodide/triiodide redox mediator in dye-sensitized solar cells. Acc. Chem. Res. 42, 1819-1826. doi: 10.1021/ar900138m

Cao, Y. M., Liu, Y. H., Zakeeruddin, S. M., Hagfeldt, A., and Gratzel, M. (2018). Direct contact of selective charge extraction layers enables high-efficiency molecular photovoltaics. Joule 2, 1108-1117. doi: 10.1016/j.joule.2018.03.017

Cappel, U. B., Gibson, E. A., Hagfeldt, A., and Boschloo, G. (2009). Dye regeneration by spiro-MeOTAD in solid state dye-sensitized solar cells studied by photoinduced absorption spectroscopy and spectroelectrochemistry. J. Phys. Chem. C 113, 6275-6281. doi: 10.1021/jp811196h

Ellis, H., Jiang, R., Ye, S., Hagfeld, A., and Boschloo, G. (2016). Development of high efficiency $100 \%$ aqueous cobalt electrolyte dye-sensitised solar cells. Phys. Chem. Chem. Phys. 18, 8419-8427. doi: 10.1039/C6CP00264A

Feldt, S. M., Gibson, E. A., Gabrielsson, E., Sun, L., Boschloo, G., and Hagfeldt, A. (2010). Design of organic dyes and cobalt polypyridine redox mediators for high-efficiency dye-sensitized solar cells. J. Am. Chem. Soc. 132, 16714-16724. doi: $10.1021 /$ ja1088869

Freitag, M., Daniel, Q., Pazoki, M., Sveinbjornsson, K., Zhang, J. B., Sun, L. C., et al. (2015). High-efficiency dye-sensitized solar cells with molecular copper phenanthroline as solid hole conductor. Energy Environ. Sci. 8, 2634-2637. doi: 10.1039/C5EE01204J

Freitag, M., Giordano, F., Yang, W. X., Pazoki, M., Hao, Y., Zietz, B., et al. (2016). Copper phenanthroline as a fast and high-performance redox mediator for dye-sensitized solar cells. J. Phys. Chem. C 120, 9595-9603. doi: 10.1021/acs.jpcc.6b01658

Green, M. A. (2012). Limiting photovoltaic efficiency under new ASTM International G173-based reference spectra. Prog. Photovoltaics 20, 954-959. doi: 10.1002/pip.1156

Hagfeldt, A., Boschloo, G., Sun, L., Kloo, L., and Pettersson, H. (2010). Dyesensitized solar cells. Chem. Rev. 110, 6595-6663. doi: 10.1021/cr900356p

Han, L. Y., Islam, A., Chen, H., Malapaka, C., Chiranjeevi, B., Zhang, S. F., et al. (2012). High-efficiency dye-sensitized solar cell with a novel co-adsorbent. Energy Environ. Sci. 5, 6057-6060. doi: 10.1039/c2ee03418b

Han, L. Y., Koide, N., Chiba, Y., Islam, A., Komiya, R., Fuke, N., et al. (2005). Improvement of efficiency of dye-sensitized solar cells by reduction of internal resistance. Appl. Phys. Lett. 86:213501. doi: 10.1063/1.1925773

Hao, Y., Saygili, Y., Cong, J. Y., Eriksson, A., Yang, W. X., Zhang, J. B., et al. (2016a). Novel blue organic dye for dye-sensitized solar cells achieving high efficiency in cobalt-based electrolytes and by co-sensitization. Acs Appl. Mater. Interfaces 8, 32797-32804. doi: 10.1021/acsami.6b09671

Hao, Y., Yang, W. X., Zhang, L., Jiang, R., Mijangos, E., Saygili, Y., et al. (2016b). A small electron donor in cobalt complex electrolyte significantly improves efficiency in dye-sensitized solar cells. Nat. Commun. 7:13934. doi: 10.1038/ncomms13934

Haque, S. A., Palomares, E., Cho, B. M., Green, A. N. M., Hirata, N., Klug, D. R., et al. (2005). Charge separation versus recombination in dye-sensitized nanocrystalline solar cells: the minimization of kinetic redundancy. J. Am. Chem. Soc. 127, 3456-3462. doi: 10.1021/ja0460357

Haque, S. A., Tachibana, Y., Willis, R. L., Moser, J. E., Grätzel, M., David, R., et al. (2000). Parameters influencing charge recombination kinetics in

\section{AUTHOR CONTRIBUTIONS}

The author confirms being the sole contributor of this work and has approved it for publication.

\section{ACKNOWLEDGMENTS}

STandUP for Energy is acknowledged for funding.

dye-sensitized nanocrystalline titanium dioxide films. J. Phys. Chem. B 104, 538-547. doi: 10.1021/jp991085x

Hore, S., Nitz, P., Vetter, C., Prahl, C., Niggemann, M., and Kern, R. (2005). Scattering spherical voids in nanocrystalline $\mathrm{TiO}_{2}$ - enhancement of efficiency in dye-sensitized solar cells. Chem. Commun. 15, 2011-2013. doi: 10.1039/b418658n

Ito, S., Murakami, T. N., Comte, P., Liska, P., Gratzel, C., Nazeeruddin, M. K., et al. (2008). Fabrication of thin film dye sensitized solar cells with solar to electric power conversion efficiency over 10\%. Thin Solid Films 516, 4613-4619. doi: 10.1016/j.tsf.2007.05.090

Kakiage, K., Aoyama, Y., Yano, T., Oya, K., Fujisawa, J., and Hanaya, M. (2015). Highly-efficient dye-sensitized solar cells with collaborative sensitization by silyl-anchor and carboxy-anchor dyes. Chem. Commun. 51, 15894-15897. doi: 10.1039/C5CC06759F

Kakiage, K., Osada, H., Aoyama, Y., Yano, T., Oya, K., Iwamoto, S., et al. (2016). Achievement of over $1.4 \mathrm{~V}$ photovoltage in a dye-sensitized solar cell by the application of a silyl-anchor coumarin dye. Sci. Rep. 6:35888. doi: $10.1038 /$ srep35888

Kay, A., and Grätzel, M. (2002). Dye-sensitized core-shell nanocrystals: improved efficiency of mesoporous tin oxide electrodes coated with a thin layer of an insulating oxide. Chem. Mater. 14, 2930-2935. doi: 10.1021/cm0115968

Kumara, G., Tennakone, K., Perera, V. P. S., Konno, A., Kaneko, S., and Okuya, M. (2001). Suppression of recombinations in a dye-sensitized photoelectrochemical cell made from a film of tin IV oxide crystallites coated with a thin layer of aluminium oxide. J. Phys. D-Appl. Phys. 34, 868-873. doi: 10.1088/0022-3727/34/6/306

Law, C., Pathirana, S. C., Li, X., Anderson, A. Y., Barnes, P. R. F., Listorti, A., et al. (2010). Water-based electrolytes for dye-sensitized solar cells. Adv. Mater. 22, 4505-4509. doi: 10.1002/adma.201001703

Mathew, S., Yella, A., Gao, P., Humphry-Baker, R., Curchod, B. F. E., AshariAstani, N., et al. (2014). Dye-sensitized solar cells with $13 \%$ efficiency achieved through the molecular engineering of porphyrin sensitizers. Nat. Chem. 6, 242-247. doi: 10.1038/nchem.1861

Melas-Kyriazi, J., Ding, I. K., Marchioro, A., Punzi, A., Hardin, B. E., Burkhard, G. F., et al. (2011). The effect of hole transport material pore filling on photovoltaic performance in solid-state dye-sensitized solar cells. Adv. Energy Mater. 1, 407-414. doi: 10.1002/aenm.201100046

Nusbaumer, H., Moser, J. E., Zakeeruddin, S. M., Nazeeruddin, M. K., and Gratzel, M. (2001). Co-II(dbbiP)(2)(2+) complex rivals tri-iodide/iodide redox mediator in dye-sensitized photovoltaic cells. J. Phys. Chem. B 105, 10461-10464. doi: 10.1021/jp012075a

Ogura, R. Y., Nakane, S., Morooka, M., Orihashi, M., Suzuki, Y., and Noda, K. (2009). High-performance dye-sensitized solar cell with a multiple dye system. Appl. Phys. Lett. 94:073308. doi: 10.1063/1.3086891

O’Regan, B., and Grätzel, M. (1991). A low-cost, high-efficiency solar cell based on dye-sensitized colloidal titanium dioxide films. Nature 353, 737-740. doi: $10.1038 / 353737 \mathrm{a} 0$

Ren, Y. M., Sun, D. Y., Cao, Y. M., Tsao, H. N., Yuan, Y., Zakeeruddin, S. M., et al. (2018). A stable blue photosensitizer for color palette of dye-sensitized solar cells reaching $12.6 \%$ efficiency. J. Am. Chem. Soc. 140, 2405-2408. doi: $10.1021 /$ jacs.7b12348

Sapp, S. A., Elliott, C. M., Contado, C., Caramori, S., and Bignozzi, C. A. (2002) Substituted polypyridine complexes of cobalt(II/III) as efficient electrontransfer mediators in dye-sensitized solar cells. J. Am. Chem. Soc. 124, 11215-11222. doi: 10.1021/ja027355y 
Saygili, Y., Soderberg, M., Pellet, N., Giordano, F., Cao, Y. M., Munoz-Garcia, A. B., et al. (2016). Copper bipyridyl redox mediators for dye-sensitized solar cells with high photovoltage. J. Am. Chem Soc. 138, 15087-15096. doi: 10.1021/jacs.6b10721

Shen, Z. J., Xu, B., Liu, P., Hu, Y., Yu, Y., Ding, H. R., et al. (2017). High performance solid-state dye-sensitized solar cells based on organic blue-colored dyes. J. Mater. Chem. A 5, 1242-1247. doi: 10.1039/C6TA09723E

Shibayama, N., Ozawa, H., Abe, M., Ooyama, Y., and Arakawa, H. (2014). A new cosensitization method using the Lewis acid sites of a $\mathrm{TiO}_{2}$ photoelectrode for dye-sensitized solar cells. Chem. Commun. 50, 6398-6401. doi: 10.1039/C3CC49461F

Snaith, H. J., Humphry-Baker, R., Chen, P., Cesar, I., Zakeeruddin, S. M., and Grätzel, M. (2008). Charge collection and pore filling in solid-state dye-sensitized solar cells. Nanotechnology 19:424003. doi: 10.1088/0957-4484/19/42/424003

Wang, Y., and Hamann, T. W. (2018). Improved performance induced by in situ ligand exchange reactions of copper bipyridyl redox couples in dye-sensitized solar cells. Chem. Commun. 54, 12361-12364. doi: 10.1039/C8CC07191H

Wang, Z. S., Kawauchi, H., Kashima, T., and Arakawa, H. (2004). Significant influence of $\mathrm{TiO}_{2}$ photoelectrode morphology on the energy conversion efficiency of N719 dye-sensitized solar cell. Coord. Chem. Rev. 248, 1381-1389. doi: 10.1016/j.ccr.2004.03.006

Yella, A., Lee, H. W., Tsao, H. N., Yi, C., Chandiran, A. K., Nazeeruddin, M. K., et al. (2011). Porphyrin-sensitized solar cells with cobalt (II/III) based redox electrolyte exceed 12 percent efficiency. Science 334, 629-634. doi: $10.1126 /$ science. 1209688

Yum, J. H., Baranoff, E., Kessler, F., Moehl, T., Ahmad, S., Bessho, T., et al. (2012). A cobalt complex redox shuttle for dye-sensitized solar cells with high open-circuit potentials. Nat. Commun. 3:631. doi: 10.1038/ ncomms1655

Zhang, Q. F., Dandeneau, C. S., Zhou, X. Y., and Cao, G. Z. (2009). ZnO nanostructures for dye-sensitized solar cells. Adv. Mater. 21, 4087-4108. doi: 10.1002/adma.200803827

Zhang, W., Wu, Y., Bahng, H. W., Cao, Y., Yi, C., Saygili, Y., et al. (2018). Comprehensive control of voltage loss enables $11.7 \%$ efficient solid-state dye-sensitized solar cells. Energy Environ. Sci. 11, 1779-1787. doi: 10.1039/C8EE00661J

Conflict of Interest Statement: The author declares that the research was conducted in the absence of any commercial or financial relationships that could be construed as a potential conflict of interest.

Copyright $\odot 2019$ Boschloo. This is an open-access article distributed under the terms of the Creative Commons Attribution License (CC BY). The use, distribution or reproduction in other forums is permitted, provided the original author $(s)$ and the copyright owner(s) are credited and that the original publication in this journal is cited, in accordance with accepted academic practice. No use, distribution or reproduction is permitted which does not comply with these terms. 